\title{
Low-dose subconjunctival bevacizumab to augment trabeculectomy for glaucoma
}

This article was published in the following Dove Press journal:

Clinical Ophthalmology

16 June 201 I

Number of times this article has been viewed

Mohammad-Reza Sedghipour

Ali Mostafaei

Yousef Taghavi

Nikoukari Ophthalmology University Hospital, Tabriz University of Medical Sciences, Tabriz, Iran
Correspondence:Ali Mostafaei

Nikoukari University Hospital,

Abbasi St, Tabriz, Iran

Tel/fax +98 4II 3342219

Email alimostafaie@yahoo.com
Background: The purpose of this study was to assess the effect of bevacizumab in maintaining intraocular pressure lowered by trabeculectomy in refractory open-angle glaucoma.

Methods: Thirty-seven eyes from 37 patients referring to Nikoukari Ophthalmology University Hospital in Tabriz were enrolled in this randomized clinical trial. Seventeen patients were randomly assigned to receive bevacizumab augmentation after trabeculectomy, and 20 patients were assigned to a control group receiving a placebo injection of normal saline. Bevacizumab was injected subconjunctivally at a dose of $0.2 \mathrm{mg}$. Intraocular pressure was measured on eight occasions, ie, at baseline, 24 hours, 3 days, 7 days, 2 weeks, 1 month, 2 months, and 3 months after treatment.

Results: Men constituted $81 \%$ of the participants, who were of mean age 67.5 years. Twenty-nine patients had secondary open-angle glaucoma, while eight patients had primary open-angle glaucoma. Intraocular pressure decreased from a mean of $28.4 \mathrm{mmHg}$ at baseline to a mean of $12.1 \mathrm{mmHg}$ during the first day and to $15.1 \mathrm{mmHg}$ after 3 months. Adding bevacizumab to trabeculectomy was not found to affect intraocular pressure differently to placebo. Neither the results of repeated measurements analysis nor single comparison statistical tests were significant for a difference in efficacy of bevacizumab versus placebo.

Conclusion: Subconjunctival bevacizumab $0.2 \mathrm{mg}$ was not found to affect the trend in intraocular pressure more than placebo after trabeculectomy for open-angle glaucoma.

Keywords: glaucoma, trabeculectomy, bevacizumab, antivascular endothelial growth factor agents

\section{Introduction}

Fibroblast proliferation and subsequent scar formation at the surgical site is the main reason for failure of filtering surgery. Antimetabolites, such as mitomycin $\mathrm{C}$ and 5-fluorouracil, have been used to modify the wound healing response and to prevent bleb failure. Research has showed these two methods to be effective in augmenting trabeculectomy. ${ }^{1-6}$ However, they have not proven to be fully satisfactory, and research is ongoing to identify and test other alternatives. Considering the essential role of angiogenesis in the proliferative phase of wound healing and the pathological process in bleb failure after trabeculectomy, researchers have thought of using antiangiogenesis agents to slow this process after filtration surgery. Bevacizumab (Avastin ${ }^{\circledR}$ ) is an antivascular endothelial growth factor agent of interest in this regard, both for neovascular and other types of glaucoma research. However, evidence for its efficacy in augmentation of filtration surgery is very limited. Only a few quite small-sized studies are available, most of them being case series. The aim of this study was to assess the effect of 
bevacizumab in maintaining intraocular pressure lowered by trabeculectomy in refractory open-angle glaucoma.

\section{Methods}

A randomized clinical trial was conducted at the Nikoukari Ophthalmology University Hospital in Tabriz, Iran. Thirty-seven eyes from 37 patients were included. Nearly half of the patients had bilateral glaucoma. For these patients, the eye being more refractory to treatment, they were enrolled into the study. Using simple randomization for a parallel trial design, 17 patients were randomly assigned to receive bevacizumab (Roche, Basel, Switzerland) augmentation after trabeculectomy, and 20 patients were assigned to a control group receiving a normal saline injection as a placebo after trabeculectomy. After fornix-based trabeculectomy 8-10 mm from the bleb, bevacizumab was injected subconjunctivally at a dose of $0.2 \mathrm{mg}$ in the active treatment group, and normal saline was injected in a similar manner into the subconjunctiva in the placebo-treated group.

A simple randomization method was used to allocate the patients to receive either bevacizumab or placebo injection after trabeculectomy. Unlike block randomization, simple randomization does not ensure an equal number of patients in both arms of the study, but it does ensure a probabilistic status. The study was double-blinded such that neither patient nor the surgeon knew the type of treatment administered. To ensure blinding, an ophthalmology resident was responsible for preparation of the injection syringes, such that their content was not identifiable to the surgeon.

The inclusion criteria for this study were primary or secondary open-angle glaucoma and uncontrolled intraocular pressure. The exclusion criteria were age under 40 years, increased intraocular pressure due to neovascular inflammation, aphakic glaucoma, and traumatic glaucoma. Patients were followed up for measurement of intraocular pressure and any development of complications. Intraocular pressure was measured in eight occasions, ie, at baseline, 24 hours, 3 days, 7 days, 2 weeks, 1 month, 2 months, and 3 months after treatment. The primary endpoint of the study was the intraocular pressure measurement trend on a continuous scale.

\section{Statistical analysis}

Data were analyzed using STATA statistical software package (v 11; College Station, TX). Trends in intraocular pressure were compared between groups at evaluation sessions throughout the study. Mean and median tests were also used to compare intraocular pressure between the groups.
Considering the placebo-controlled design of the trial, the statistical tests were done in a one-sided manner, giving higher power to the study. Test results with a $P$-value lower than 0.05 were considered to be statistically significant. The study protocol was approved by the committee of ethics at Tabriz University of Medical Sciences.

\section{Results}

Men constituted $81 \%$ of the participants. The mean patient age was 67.5 (range 48-83) years, with a standard deviation (SD) of 10 years. Twenty-nine patients had secondary openangle glaucoma, and eight patients had primary open-angle glaucoma. Nineteen right and 18 left eyes were operated on, and the distribution was not different between the groups. The mean cup-to-disc ratio was $0.9 \pm 0.16$, and this was not statistically different between the two treatment groups. Mean corneal thickness was 517.6, and this was not statistically different between the groups.

Overall, mean intraocular pressure deceased significantly just shortly after surgery, from a mean of $28.4 \mathrm{mmHg}$ at baseline to a mean of $12.1 \mathrm{mmHg}$ on the first day and to $15.1 \mathrm{mmHg}$ after 3 months. This decrement was statistically significant $(P<0.001)$ at both time points. As shown in Figure 1, the intraocular pressure decreased sharply on the first day and reached a plateau during the first 2 weeks, thereafter increasing to another plateau 1 month after treatment, then staying rather stable for the rest of the follow-up period.

Descriptive statistics for intraocular pressure were compared between the treatment groups, as shown in Table 1. Adding bevacizumab to trabeculectomy was not found to affect intraocular pressure more than placebo. Neither results

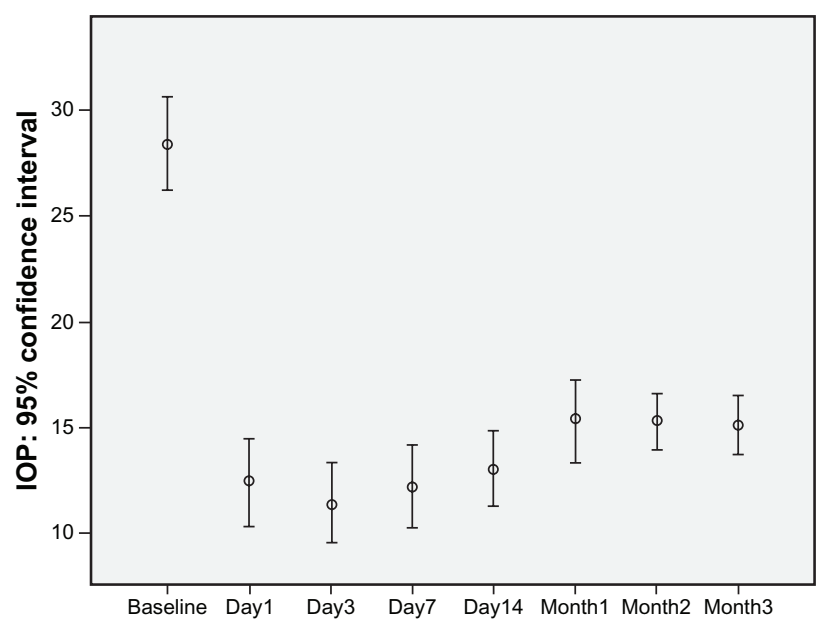

Figure I Error bar graph of intraocular pressure evaluated at baseline and several times after surgery for all patients. Middle circle represents the mean intraocular pressure, and the bars show the $95 \%$ confidence intervals of mean intraocular pressure. Abbreviation: IOP, intraocular pressure. 
Table I Intraocular pressure compared between trabeculectomy augmented by bevacizumab versus placebo

\begin{tabular}{|c|c|c|c|c|c|c|}
\hline \multirow{2}{*}{$\begin{array}{l}\text { Assessment } \\
\text { time }\end{array}$} & \multicolumn{2}{|c|}{ Avastin } & \multicolumn{2}{|c|}{ Placebo } & \multicolumn{2}{|c|}{ Comparison } \\
\hline & Mean & SD & Mean & SD & $\begin{array}{l}\text { Mean } \\
\text { difference }\end{array}$ & $\begin{array}{l}\text { Statistical } \\
\text { significance }\end{array}$ \\
\hline Baseline & 27.9 & 1.4 & 28.7 & 1.6 & & \\
\hline Day I & 11.7 & 1.5 & 12.6 & 1.6 & -0.9 & NS \\
\hline Day 3 & 10.9 & 1.6 & 11.9 & I & -1 & NS \\
\hline Day 7 & 11.9 & 1.5 & 12.4 & 1.3 & -0.5 & NS \\
\hline Day 14 & 12.5 & $\mathrm{I} .4$ & 13.6 & I.I & -1.1 & NS \\
\hline Month I & 15.3 & I.I & 15.3 & 1.5 & 0 & NS \\
\hline Month 2 & 15.4 & 0.9 & 15.2 & 0.9 & 0.2 & NS \\
\hline Month 3 & I5.1 & I & 15.1 & 1 & 0 & NS \\
\hline
\end{tabular}

Abbreviation: NS, not statistically significant; SD, standard deviation.

of repeated measurement analysis nor single comparison statistical tests were significant for a difference in efficacy of bevacizumab compared with placebo when used after trabeculectomy for glaucoma. Table 1 shows that the transiently lower intraocular pressure effect of bevacizumab disappears 1 month after treatment. No serious complication from bevacizumab was recorded in this study.

\section{Discussion}

Well vascularized blebs have been shown to be associated with a poorer prognosis than less vascular blebs. ${ }^{7}$ The effects of angiogenesis inhibitors on Tenon's fibroblast proliferation and migration define the antifibroblastic properties of the antivascular endothelial growth factor agents, including bevacizumab. Although the antiangiogenic effects of these agents make them applicable for neovascular glaucoma, the discovery that antivascular endothelial growth factor has antifibroblastic effects has led researchers to think of using these agents to augment glaucoma filtration surgery, in the hope of delaying or reducing the bleb failure rate. ${ }^{8}$ Bevacizumab is an antivascular endothelial growth factor agent thought to be potentially applicable in increasing bleb survival after trabeculectomy for glaucoma. Few studies have addressed this issue, and have used different methodologies.

Studies of the in vitro effects of bevacizumab on human corneal and conjunctival fibroblast cell lines have been controversial. ${ }^{9,10}$ A recent animal study showed that subconjunctival bevacizumab after trabeculectomy improved bleb survival. ${ }^{11}$ Human studies are quite limited in this regard. Choi et al reported the results of their case series comprising six refractory glaucomatous eyes. They administered subconjunctival bevacizumab $1.25 \mathrm{mg}$ after trabeculectomy augmented with mitomycin C. Based on the favorable results of this study, they have suggested that subconjunctival bevacizumab may be effective in improving the efficacy of trabeculectomy. ${ }^{12}$
However, definitive conclusions regarding the efficacy of a treatment are not usually expected to be drawn from a case series, and the situation is much more complex in their study because of the concomitant use of mitomycin C. A few further case reports and case series have also discussed the role of bevacizumab in trabeculectomy, but suffer similar study limitations. ${ }^{13-17}$

In a pilot study, Grewal et al used bevacizumab $1.25 \mathrm{mg}$ by subconjunctival injection after trabeculectomy in 12 patients. Mean intraocular pressure in their study decreased from $24.4 \mathrm{mmHg}$ to $8.3 \mathrm{mmHg}$ during the first day, and increased slightly in the following 3 months. ${ }^{18}$ Their study lacked a control group, making it near impossible to separate the effect of bevacizumab from the effect of surgery. We did not observe any significant difference between our placebo and bevacizumab groups, and any trivial nonsignificant differences disappeared over time. In our study, we found two intraocular pressure plateaus suggestive of decayed efficacy of treatment, so repeated injections may be necessary, even if bevacizumab is found to be effective. ${ }^{19,20}$

In interpreting the findings of our study, it should be taken into account that, although it was not a large-scale study and lower statistical power may explain its results, it is the largest study to date when compared with other published research using a similar study design. Another point needing attention is the lower dose of drug and also the fact that, in contrast with most previous studies, neovascular glaucoma was an exclusion criterion in our study.

\section{Conclusion}

Single-dose subconjunctival bevacizumab $0.2 \mathrm{mg}$ was not found to affect the intraocular pressure trend in a way that was significantly different from placebo when administered to augment filtration surgery in refractory glaucomatous eyes, and any trivial drug effect decayed over time. Of note is that this study was conducted with a 3-month evaluation period and, although this length of time was sufficient to detect decay of efficacy, future studies with larger sample sizes and longer periods of evaluation are warranted.

\section{Disclosure}

The authors report no conflicts of interest in this work.

\section{References}

1. WuDunn D, Cantor LB, Palanca-Capistrano AM, et al. A prospective randomized trial comparing intraoperative 5-fluorouracil vs mitomycin C in primary trabeculectomy. Am J Ophthalmol. 2002;134(4):521-528.

2. Wormald R, Wilkins MR, Bunce C. Post-operative 5-Fluorouracil for glaucoma surgery. Cochrane Database Syst Rev. 2001;(3):CD001132. 
3. Wilkins $\mathrm{M}$, Indar $\mathrm{A}$, Wormald $\mathrm{R}$. Intra-operative mitomycin $\mathrm{C}$ for glaucoma surgery. Cochrane Database Syst Rev. 2005;(4):CD002897.

4. Singh K, Egbert PR, Byrd S, et al. Trabeculectomy with intraoperative 5-fluorouracil vs mitomycin C. Am J Ophthalmol. 1997;123(1):48-53.

5. Singh K, Mehta K, Shaikh NM, et al. Trabeculectomy with intraoperative mitomycin $\mathrm{C}$ versus 5 -fluorouracil. Prospective randomized clinical trial. Ophthalmology. 2000;107(12):2305-2309.

6. Mostafaei A. Augmented trabeculectomy in glaucoma by subconjunctival mitomycin $\mathrm{C}$ versus subconjunctival 5-fluorouracil: A randomized clinical trial. Clin Ophthalmol. 2011;5:491-494.

7. Jampel HD, McGuigan LJ, Dunkelberger GR, L'Hernault NL, Quigley HA. Cellular proliferation after experimental glaucoma filtration surgery. Arch Ophthalmol. 1988;106(1):89-94.

8. Wong J, Wang N, Miller JW, Schuman JS. Modulation of human fibroblast activity by selected angiogenesis inhibitors. Exp Eye Res. 1994; 58(4):439-451.

9. Yoeruek E, Spitzer MS, Tatar O, Aisenbrey S, Bartz-Schmidt KU, Szurman P. Safety profile of bevacizumab on cultured human corneal cells. Cornea. 2007;26(8):977-982.

10. Horsley MB, Kahook MY. Anti-VEGF therapy for glaucoma. Curr Opin Ophthalmol. 2010;21(2):112-117.

11. Memarzadeh F, Varma R, Lin LT, et al. Postoperative use of bevacizumab as an antifibrotic agent in glaucoma filtration surgery in the rabbit. Invest Ophthalmol Vis Sci. 2009;50(7):3233-3237.
12. Choi JY, Choi J, Kim YD. Subconjunctival bevacizumab as an adjunct to trabeculectomy in eyes with refractory glaucoma: A case series. Korean J Ophthalmol. 2010;24(1):47-52.

13. Coote MA, Ruddle JB, Qin Q, Crowston JG. Vascular changes after intrableb injection of bevacizumab. J Glaucoma. 2008;17(7):517-518.

14. Cornish KS, Ramamurthi S, Saidkasimova S, Ramaesh K. Intravitreal bevacizumab and augmented trabeculectomy for neovascular glaucoma in young diabetic patients. Eye (Lond). 2009;23(4):979-981.

15. Jonas JB, Spandau UH, Schlichtenbrede F. Intravitreal bevacizumab for filtering surgery. Ophthalmic Res. 2007;39(2):121-122.

16. Kahook MY, Schuman JS, Noecker RJ. Needle bleb revision of encapsulated filtering bleb with bevacizumab. Ophthalmic Surg Lasers Imaging. 2006;37(2):148-150.

17. Gheith ME, Siam GA, de Barros DS, Garg SJ, Moster MR. Role of intravitreal bevacizumab in neovascular glaucoma. J Ocul Pharmacol Ther. 2007;23(5):487-491.

18. Grewal DS, Jain R, Kumar H, Grewal SP. Evaluation of subconjunctival bevacizumab as an adjunct to trabeculectomy a pilot study. Ophthalmology. 2008;115(12):2141-2145.

19. Gheith ME, Siam GA, de Barros DS, Garg SJ, Moster MR. Role of intravitreal bevacizumab in neovascular glaucoma. $J$ Ocul Pharmacol Ther. 2007;23(5):487-491.

20. Jue A. Angiogenesis: Trabeculectomy and bevacizumab. Semin Ophthalmol. 2009;24(2):122-125.
Clinical Ophthalmology

\section{Publish your work in this journal}

Clinical Ophthalmology is an international, peer-reviewed journal covering all subspecialties within ophthalmology. Key topics include: Optometry; Visual science; Pharmacology and drug therapy in eye diseases; Basic Sciences; Primary and Secondary eye care; Patient Safety and Quality of Care Improvements. This journal is indexed on

\section{Dovepress}

PubMed Central and CAS, and is the official journal of The Society of Clinical Ophthalmology (SCO). The manuscript management system is completely online and includes a very quick and fair peer-review system, which is all easy to use. Visit http://www.dovepress.com/ testimonials.php to read real quotes from published authors. 